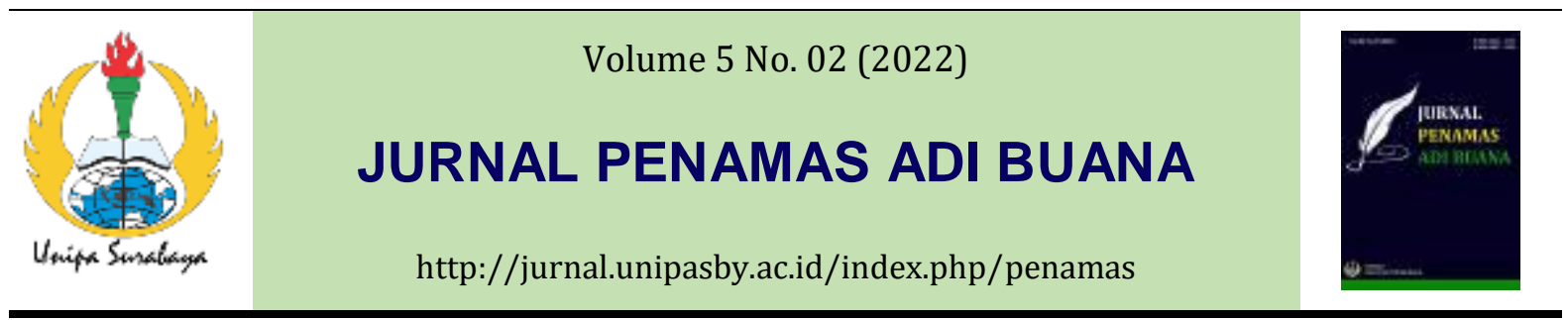

\title{
MESIN PENYIRAMAN OTOMATIS BERBASIS TIMER SEBAGAI ALAT PERAWATAN TANAMAN DI TAMAN SEHAT DESA SEGORO TAMBAK KEC. SEDATI KAB. SIDOARJO
}

\author{
Moch. Hendrawan Hidayat ${ }^{1}$, Syahrun Ramadhana Al Dino ${ }^{2}$, \\ Khumairoh Nur'Aini ${ }^{3}$, Ervin Nurul Affrida ${ }^{4}$ \\ ${ }^{1}$ Teknik Industri FTSP Universitas PGRI Adi Buana Surabaya \\ ${ }^{2}$ Pend. Bahasa Inggris FISH Universitas PGRI Adi Buana Surabaya \\ ${ }^{3}$ PGSD FPP Universitas PGRI Adi Buana Surabaya \\ ${ }^{4}$ PG-PAUD FPP Universitas PGRI Adi Buana Surabaya \\ Email: ervina@unipasby.ac.d
}

\begin{abstract}
Informasi Artikel Abstrak
Kata kunci:

Mesin penyiraman,

Taman, Inovasi

Diterima: 10-01-2022

Disetujui: 25-01-2022

Dipubikasikan: 31-01-

2022

Salah satu tahapan penting dalam bercocok tanam pada lahan adalah penyiraman tanaman. Terdapat dua jenis cara menyiram tanaman yaitu secara manual dan otomatis. Penyiraman tanaman secara manual dengan cara mengambil air dari sumur atau sumber air terdekat, menggunakan selang dan seterusnya. Selanjutnya, penyiraman tanaman secara otomatis dapat menggunakan media tertentu seperti mesin penyiraman otomatis yang didesain sesuai karakteristik lahan bercocok tanam. Adapun prinsip kerja mesin penyiram otomatis ini yaitu menyemprotkan air yang telah disediakan untuk asupan hidrogan pada tanaman pada jam dan waktu yang ditentukan. Mesin penyiraman otomatis merupakan salah satu inovasi pada program Kuliah Kerja Nyata-Tematik Reguler (KKN-TR) Universitas PGRI Adi Buana Surabaya. Inovasi mesin penyiraman otomatis berbasis timer ditempatkan pada taman di lokasi KKN-TR sehingga dapat membantu efisiensi tenaga dan waktu dalam perawatan tanaman. Adapun lokasinya berada di Taman Sehat Desa Segoro Tambak Kec. Sedati Kab. Sidoarjo. Hasil kegiatan dalam bentuk alat penyiraman otomatis berbasis timer yang dipasang pada taman di Desa Segoro Tambak Kec. Sedati Kab. Sidorajo. Melalui inovasi alat penyiraman otomatis tersebut, tanaman di taman desa dapat terpenuhi kebutuhan air berdasarkan analisis ph tanah serta rentang waktu yang telah diatur pada alat penyiraman.

\section{Abstract}

Keywords :

watering machine, Park, Innovation
One of the important stages in farming on land is watering plants. There are two types of watering plants, namely manually and automatically. Watering plants manually by taking water from a well or the nearest water source, using a hose and so on. Furthermore, watering plants can automatically use certain media such as automatic watering machines that are designed according to the characteristics of the land for farming. The working principle of this automatic sprinkler machine is to spray the water that has been provided for the intake of hydrogen to the plants at the specified hour and time. The automatic watering machine is one of the innovations in the 
Regular Thematic Real Work Lecture (KKN-TR) Universitas PGRI Adi Buana Surabaya. The innovation of a timer-based automatic watering machine is placed in the garden at the KKN-TR location so that it can help save energy and time in plant care. The location is in the Healthy Park, Segoro Tambak Village, Kec. Sedati Kab. Sidoarjo

\section{PENDAHULUAN}

Tanaman merupakan makhluk hidup penting yang tak bisa terpisahkan dengan kehidupan manusia. Air merupakan salah satu bagian terpenting untuk pertumbuhan tanaman. Tanpa perawatan intensif tanaman bisa saja mati atau layu. Perawatan tanaman harus secara intensif dan berkala agar tanaman selalu terlihat sehat dan indah sepanjang waktu. Terutama penyiraman, air juga berfungsi seagai penggembur tanah agar memudahkan akar dalam mengambil unsur hara dalam tanah dan memberi syarat yang harus dipenuhi oleh tanaman untuk fotosintesis. Dalam hal ini, tidak hanya membuat lingkungan tetap indah dan terjaga, tapi juga membantu tanaman untuk menghasilkan oksigen yang digunakan manusia untuk bernafas sehari hari.

Studi pendahuluan melalui observasi dan wawancara yang dilaksanakan pada Bulan Desember 2021 menunjukkan hasil bahwa penyiraman taman-taman di Desa Segoro Tambak Kec. Sedati Kab. Sidoarjo dilaksanakan secara manual. Adapun cara yang digunakan melalui menyiram menggunakan ember, selang penyemprot, atau tidak menyiram tanaman karena kesibukan. Hal ini berdampak pada tanaman yang mati serta menjual atau memberikan tanaman kepada orang lain karena keterbatasan waktu dalam perawatan tanaman.

Berdasarkan fenomena tersebut, mahasiswa Kuliah Kerja Nyata-Tematik Reguler (KKN-TR) Universitas PGRI Adi Buana Surabaya mendesain inovasi mesin penyiraman otomatis berbasis timer. Inovasi tersebut diharapkan dapat membantu masyarakat Desa Segoro Tambak Kec. Sedati Kab. Sidoarjo untuk perawatan tanaman sehingga efisiensi terhadap tenaga dan waktu.

\section{METODE}

Metode pelaksanaan dalam inovasi mesin penyiraman otomatis berbasis timer ini dilaksanakan dengan metode uji coba produk terbatas yaitu di Taman Sehat Desa Segoro Tambak Kec. Sedati Kab. Sidoarjo. Kegiatan awal yang dilakukan yaitu pemasangan 
perangkat yang tersedia di taman yang akan digunakan sebagai objek mesin penyiraman otomatis berbasis timer. Alat dan bahan yang digunakan dapat dilihat pada tabel 1.1 berikut:

Tabel 1.1

Alat dan Bahan Mesin Penyiraman Otomatis Berbasis Timer

\begin{tabular}{|c|c|c|}
\hline No & Alat dan Bahan & Keterangan \\
\hline 1 & Pipa Paralon $3 / 4$ & 5 Meter \\
\hline 2 & Konektor Pipa L & 2 Buah \\
\hline 3 & Konektor Pipa T & 3 Buah \\
\hline 4 & Konektor $3 / 4$ ke $1 / 2$ drat dalam & 3 Buah \\
\hline 5 & Konektor $3 / 4$ ke $1 / 2$ drat luar & 1 Buah \\
\hline 6 & Tutup Pipa $3 / 4$ & 1 Buah \\
\hline 7 & Konektor $1 / 2$ ke $5 / 16$ Selang & $1 \mathrm{Buah}$ \\
\hline 8 & Pompa high pressure & $1 \mathrm{Buah}$ \\
\hline 9 & Selang 5/16 & 2 Meter \\
\hline 10 & Stopkontak Timer & 1 Buah \\
\hline 11 & Kabel & 3 Meter \\
\hline 12 & Springkle & 3 Buah \\
\hline
\end{tabular}

Setelah menyiapkan alat dan bahan pada tabel 1.1 diatas, tahapan selanjutnya pengukuran luas keseluruhan taman untuk mengetahui panjang pipa yang diperlukan untuk jalur air pompa penyiraman otomatis. Kemudian pipa tanam pipa yang telah dipasang springkler yang menghadap ke permukaan. Penyiraman otomatis menggunakan basis timer yang berfungsi untuk mengatur waktu yang diperlukan untuk penyiraman. Pada bagian ini, stopkontak timer bekerja dua kali sehari pada jam 18.00 sd. 18.05 dan 03.00 sd. 03.05. Pengaturan waktu penyiraman tersebut bertujuan untuk menyuburkan tanaman serta menghemat daya listrik

Sistem kerja mesin penyiraman otomatis berbasis timer yaitu pompa akan menyala, selang input pada tandon akan menghisap air dan akan keluar melalui selang output menuju pipa. Air pada pipa mengarah keluar melalui 3 springkler. Air akan keluar jika tekanan yang dihasilkan pompa kuat. Setelah 5 menit berlalu timer akan memutus hubungan listrik dari sumber menuju ke pompa sehingga pompa akan mati dan springkler tidak mengeluarkan air. 
Pompa mati atau hidup tergantung dengan settingan yang kita lakukan sebelumnya pada timer.

\section{HASIL DAN PEMBAHASAN}

Setelah dilakukan pembuatan dan pemasangan mesin penyiraman otomatis untuk taman di Desa Segoro Tambak Kec. Sedati Kab. Sidoarjo dapat digambarkan bahwa mesin penyiraman otomatis memiliki flowchart pada gambar 1.1 berikut:

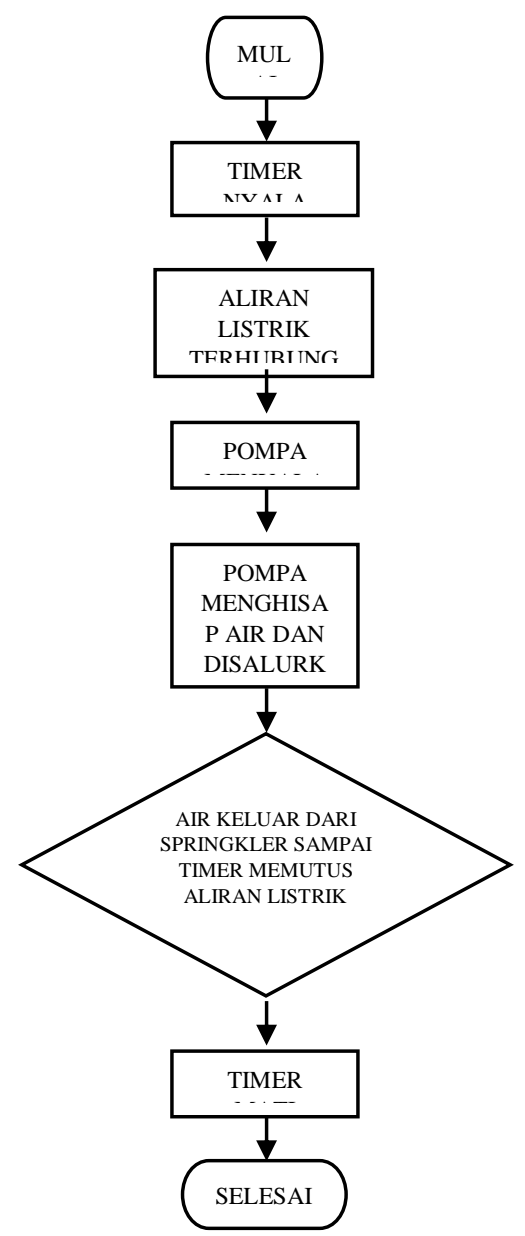

\section{Gambar 1.1 Cara Kerja Mesin Penyiraman Otomatis}

Berdasarkan gambar 1.1 diatas, cara pengoperasian mesin penyiram otomatis berbasis timer yaitu pastikan sumber daya utama sudah nyala kemudian pengaturan waktu otomatis sehingga akan membuka aliran listrik menuju pompa. Langkah selanjutnya mesin pompa akan otomatis menyala karena adanya arus listrik dari adaptor dengan tegangan 12v DC. Selang input pada tandon akan menghisap air dan akan keluar melalui selang output yang menuju pipa. Setelah proses tersebut air pada pipa mengarah keluar melalui 3 springkler sehingga air akan keluar jika tekanan yang dihasilkan pompa kuat. Setelah 5 menit timer akan 
memutus aliran listrik dari sumber menuju ke pompa sehingga springkler tidak mengeluarkn air karena tekanan air menuju springkler kurang.

Setelah mesin penyiraman otomatis selesai dirancang, selanjutnya mengadakan pengujian alat dengan membandingkan penggunaan penyiram air berbasis energi manusia dengan mesin penyiraman otomatis yang telah dirancang. Adapun proses pengujian mesin penyiraman otomatis dapat dilihat pada gambar 1.2 dibawah ini:

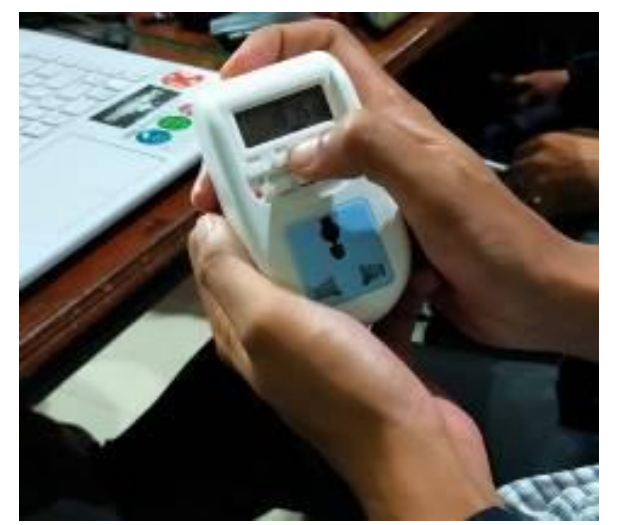

Gambar 1.2 Setting Stopkontak timer

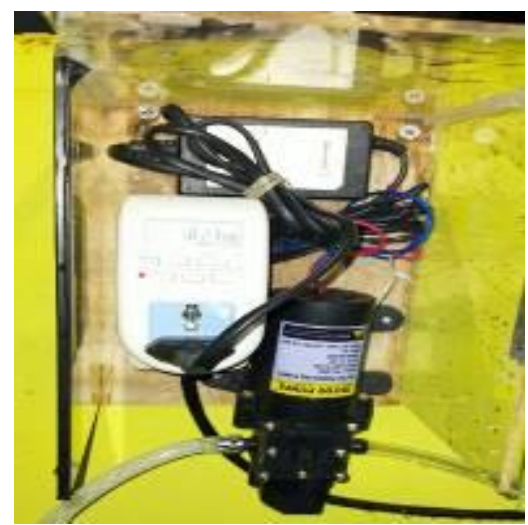

Gambar 1.3 Rangkaian mesin penyiraman otomatis

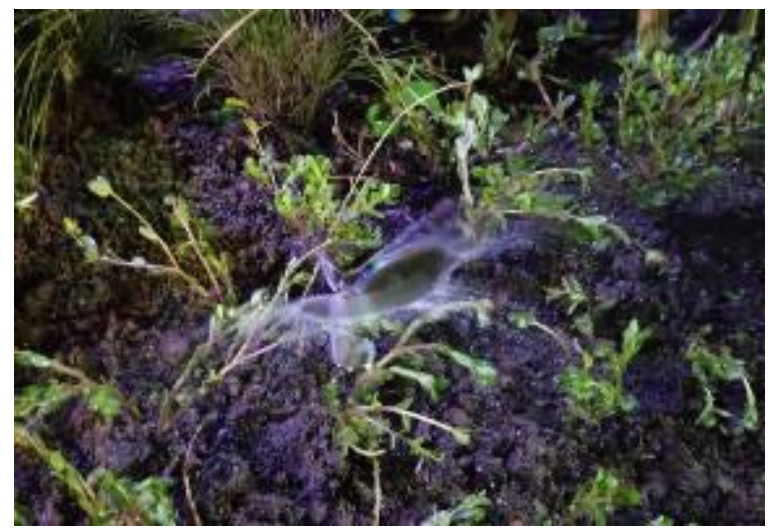

Gambar 1.4 Springkle mengeluarkan debit air sesuai dengan tekanan pompa

Berdasarkan gambar diatas menunjukkan bahwa bahwa setelah dinyalakan, pompa secara otomatis akan menyedot sumber air untuk disemprotkan keluar dan tanaman dapat tersiram secara menyeluruh. Setelah proses uji coba mesin penyiraman otomatis secara terbatas tersebut, maka langkah selanjutnya memasang mesin di taman-taman desa serta mendampingi masyarakat Desa Segoro Tambak Kec. Sedati Kab. Sidoarjo agar mampu memanfaatkan alat tersebut.

Hasil yang didapat dari pembuatan dan pemasangan pompa penyiraman air otomatis ini adalah tingkat efisienya saat proses penyiraman dilakukan. Hal ini dikarenakan pada saat pemilihan alat, tim pemasang memilih pompa air dengan high pressure sehingga dapat mengambil dan menyemburkan volume air dengan deras dan mesin yang berbentuk 
sederhana serta ringan saat diangkat. Kelebihan mesin penyiraman otomatis berbasis timer ini juga terdapat pada ketersediaan alat dan bahan yang mudah ditemukan dengan harga yang terjangkau. Melalui mesin penyiraman otomatis berbasis timer tersebut dapat memudahkan masyarakat Desa Segoro Tambak Kec. Sedati Kab. Sidoarjo dalam perawatan tanaman yang hemat listrik. Mesin penyiram tersebut menggunakan daya listrik rendah karena ukuran pompa air otomatis hampir sama dengan ukuran pompa akuarium pada umumnya. Selanjutnya dengan pertimbangan ukuran taman yang sesuai sehingga pemilihan high pressure pompa air merupakan pilihan yang ideal untuk pemasangan di taman.

Hasil yang diperoleh dari inovasi mesin penyiraman taman otomatis untuk taman Desa Segoro Tambak Kec. Sedati Kab. Sidoarjo menunjukkan hasil bahwa perawatan tanaman lebih efektif dan efisien karna waktu penyiraman dapat diatur secara otomatis. Selain itu masyarakat Desa Segoro Tambak Kec. Sedati Kab. Sidoarjo juga memperoleh pengetahuan baru serta penerapan IPTEK melalui penggunaan mesin penyiraman otomatis sehingga membantu dalam perawatan tanaman tanpa menggunakan cara manual dalam menyiram tanaman. Tanaman juga lebih terawat karena debit air disesuaikan dengan kondisi ph tanah sehingga tanaman tidak kelebihan atau kekurangan air. Tanaman yang terawat dengan mesin penyiraman otomatis membuat lingkungan Desa Segoro Tambak Kec. Sedati Kab. Sidoarjo semakin asri.

\section{KESIMPULAN}

Simpulan yang diperoleh dari pemasangan pompa penyiraman otomatis ini adalah, tidak melihat dari ukuran pompa yang relatif kecil, kekuatan yang dihasilkan juga sesuai dengan ekspektasi. Semakin besar pompa dc yang di gunakan maka semakin besar tekanan yang menyebar di springkler. Saat digunakan, penyiraman yang dihasilkan juga relatif cukup untuk mencakup luas dan lebar keseluruhan dari taman yang dipasang pompa otomatis ini. Menggunakan pompa penyiraman otomatis adalah solusi yang tepat untuk kebutuhan yang diperlukan agar senantiasa efisien dalam hal apapun. Dengan adanya pompa penyirakan otomatis, tidak hanya memberikan masyarakat keuntungan dalam waktu dan usaha, tapi juga tanaman tersebut.

\section{UCAPAN TERIMAKASIH}

Penulis mengucapkan terima kasih kepada LPPM Universitas PGRI Adi Buana Surabaya yang telah memberikan dana kegiatan sehingga pelaksanaan KKN-TR berjalan 
dengan lancar. Penulis juga mengucapkan terima kasih kepada Kepala Desa Segoro Tambak Kec. Sedati Kab. Sidoarjo beserta staf dan jajaran serta masyarakat yang telah berpartisipasi dan mendukung kegiatan KKN-TR Universitas PGRI Adi Buana Surabaya.

\section{DAFTAR PUSTAKA}

Fadhil,M., Argo,DB., Hendrawan, Y. (2015). Rancang Bangun Prototype Alat Penyiram Otomatis dengan Sistem Timer RTC DS1307 Berbasis Mikrokontroler Atmega16 pada Tanaman Aeroponik. Jurnal Keteknikan Pertanian Tropis dan Biosistem. Vol. 3 (1): 3743.

Jurney, R., (2014). Agile Data Science. Building Data Analytics Applications with Hadoop. Second Ed. ed. Sebastopol: O'Reilly.

Junaidi, Ginting. (2017). Alat Ukur Kelembaban Tanah Menggunakan Sensor YL69 Berbasis Android Phone. Journal Of Universitas Sumatera Utara Institutional Repository (USUIR)

Kafiar, Erricson Zet., Allo, Elia Kandek., \& Mamahit, Dringhuzen J. (2018). Rancang Bangun Penyiram Tanaman Berbasis Arduino Uno Menggunakan Sensor Kelembaban YL-39 dan YL-6. Jurnal Teknik Elekro dan Komputer, Vol. 7, No.3.

Kurnia. (2006). Sifat Fisik Tanah dan Metode Analisisnya. Jakarta: Balai Besar Penelitian dan Pengembangan Sumberdaya Lahan Pertanian

Pratama Yundia O., Kurniawan D,W. (2021). Rancang Bangun Mesin Pengisi dan Penakar Jamu Semi Otomatis Berbasis Timer Dan Sensor Ultrasonik. JRM. Volume 06 (2), 25 $-35$

Suganda Budi, Armentaria Jeki. 2021. Sistem Penyiraman Tanaman Otomatis Menggunakan Metode Logika Fuzzy. Journal of Applied Electrical Engineering. Vol 5 (1), 5-8.

Widhi., H. W. (2014). Sistem Penyiraman Tanaman Anggrek Menggunakan Sensor Kelembaban dengan Program Delphi 7 Berbasis Modul Arduino Uno R3, 41-45.

Yahwe, C.P., Isnawaty,\&Aksara, L. M. F. 2016. Rancang Bangun Prototype Sistem Monitoring Kelembaban Tanah Melalui SMSBerdasarkan Hasil Penyiraman Tanaman "Studi Kasus Tanaman Cabai dan Tomat". semanTIK,2(1),97-110.

Zaini, N. (2021). Rancang Bangun Penyiraman Otomatis Untuk Tanaman Hias Berbasis Mikrokontroler ESP8266. Jurnal Teknik Informatika dan Sistem Informasi. Vol. 8 (4) 2119-2130 